TITLE:

\title{
Transport of a cell-sized phospholipid micro-container across water/oil interface
}

\section{AUTHOR(S):}

Hase, Masahiko; Yamada, Ayako; Hamada, Tsutomu; Yoshikawa, Kenichi

\section{CITATION:}

Hase, Masahiko ... [et al]. Transport of a cell-sized phospholipid micro-container across water/oil interface. Chemical Physics Letters 2006, 426(4-6): 441-444

\section{ISSUE DATE:}

2006-08

URL:

http://hdl.handle.net/2433/49174

\section{RIGHT:}

Copyright (C) 2006 Elsevier B.V. All rights reserved.; This is not the published version. Please cite only the published version.; この論文は 出版社版でありません。引用の際には出版社版をご確認ご利用くださ い。 


\title{
Transport of a Cell-Sized Phospholipid Micro-Container
}

\section{Across Water/Oil Interface}

\author{
Masahiko Hase ${ }^{\mathrm{a}}$, Ayako Yamada ${ }^{\mathrm{a}}$, Tsutomu Hamada ${ }^{\mathrm{a}, 1}$ and Kenichi Yoshikawa ${ }^{\mathrm{a}, \mathrm{b} *}$ \\ ${ }^{a}$ Department of Physics, Graduate School of Science, Kyoto University, Kyoto 606-8502, Japan \\ ${ }^{\mathrm{b}}$ Spatio-Temporal Order Project, ICORP, JST
}

${ }^{*}$ Correspondence author. Fax: +81757533779.

E-mail adress: yoshikaw@scphys.kyoto-u.ac.jp (K. Yoshikawa).

${ }^{1}$ Present address: School of Material Science, Japan Advanced Institute of Science and Technology,

1-1 Asahidai, Nomi, Ishikawa 923-1292, Japan 


\section{Abstract}

When a cell-sized water droplet, with a diameter of several tens of $\mu \mathrm{m}$, is placed in oil containing phospholipids, a phospholipid monolayer is formed spontaneously on the droplet surface to produce a stable cell-sized micro-container. We report on the transportation of such 'vesicle' between an oil phase and a water phase across a lipid monolayer at the bulk water/oil interface by means of micromanipulation technique. The 'vesicle' can be returned reversibly onto the oil phase and the transportation can be performed back and forth between the two phases repeatedly. Such a vesicle-like, easily manipulable micro-container may afford a simple model of living intra-cellular environments. 


\section{Introduction}

Throughout this paper, we use the term "vesicle" to denote a spherical object composed of a phospholipid layer separating two mediums, either a water-in-oil micro droplet in oil covered by a phospholipid layer or a water-in-water micro droplet with a phospholipid membrane eventually containing a small amount of oil.

The main constituent of a cytoplasmic membrane is phospholipid molecules [1]. In aqueous solution, phospholipids spontaneously form closed bilayer vesicles, referred to as liposomes, where their acyl chains arrange in face-to-face. Recently, cell-sized liposomes (CLs) on the order of several tens of $\mu \mathrm{m}$ have been actively studied as a model of a living cell [2-8] and also as a microreactor for micro- or submicroscale biochemical reactions $[9,10]$. Although several different methodologies for preparing CLs have been reported [11-18], it is still difficult to manipulate them in a desired manner, including the encapsulation of certain substances. To make CLs with an asymmetric distribution of different kinds of phospholipids between their inner and outer leaflets also remains as a challenging research target [19].

On the other hand, it has been established that a cell-sized water droplet in oil containing phospholipids forms a stable vesicle covered by a phospholipid monolayer at the water/oil boundary as a kind of water-in-oil cell-sized emulsion (W/O CE). Such 
droplets are expected to be a prospective microreactor, since it is easy to control the size, fusion, and encapsulation of foreign substances [20-23]. It is to be noted that W/O CEs can be regarded as a simple cell model because the hydrophilic moieties of phospholipids face the water phase at the water/oil boundary, like in a cytoplasmic membrane [24].

Very recently, preliminary studies suggested that CLs can be formed from W/O CEs across a bulk water/oil interface $[7,25]$. However, direct observation of the transportation of a phospholipid vesicle across the interface has not been performed, and the physico-chemical mechanism of this transporting process has not been clarified yet. In the present study, we conducted a direct observation on the transportation of a single lipid vesicle across a bulk water/oil interface.

\section{Materials and Methods}

1,2-Dioleoyl-sn-glycero-3-phosphatidylcholine (DOPC) and Texas red 1,2-dihexadecanoyl-sn-glycero-3-phosphoethanolamine, triethylammonuim salt (Texas red DHPE) were purchased from Wako Pure Chemicals and Invitrogen, respectively. Mineral oil was obtained from Nacalai Tesque. $1 \mathrm{mM}$ DOPC and $10 \mu \mathrm{M}$ Texas red 
DHPE were dissolved in mineral oil by ultrasonication for $90 \mathrm{~min}$ at $50{ }^{\circ} \mathrm{C}$ and used within one week. To observe the vesicles transferring across the interface, we constructed macroscopically two-phase system with water/oil/phospholipid, as shown in Fig. 1; where lipid monolayer is expected to be situated at the bulk interface. We conducted observations with a phase-contrast and fluorescent microscope (Nikon TE-300) equipped with a micromanipulation system (Narishige), which enabled us to inject several picoliters of specimen and/or to move the glass capillary with a precision of a few micrometers.

\section{Results and Discussion}

Figure 2 (a) shows phase-contrast microscopic images on the process of droplet formation in the oil phase containing phospholipids by use of a glass capillary, together with the schematic illustration in Fig. 2 (b). The fluorescence micrograph in Fig. 2 (c) indicates that lipid layer surrounds the boundary of the vesicle in the oil phase. It is to be noted that the size of the vesicle can be controlled by adjusting the injection pressure or by changing the narrowness of the glass capillary.

Figure 3-I (a)-(e) exemplify phase-contrast microscopic images on the 
transportation of a vesicle across the oil/water interface. Figure 3-II represents a schematic illustration on the vesicular transformation accompanied by the transportation. It is found that a water droplet in the oil phase, a W/O CE, is sticky to the glass capillary and can be transported into a desired position through the motion of the capillary tip. As shown in Fig. 3-I (a), the droplet stuck to the capillary is easily transferred into the aqueous phase, suggesting the formation of an additional monolayer on the surface of the droplet so as to afford the hydrophilic surface in water. As will be discussed later, the vesicle, thus formed, in the aqueous phase exhibits an oil layer between the inner and outer layers of phospholipids.

Interesting to say, such vesicle can be transported back into the oil phase (Fig. 3-I (b)), and again to the water phase (Fig. 3-I (c), (d)). When the vesicle in the water phase is transported back into the oil phase, it is found that an additional outer layer is formed around the droplet at the water/oil interface, as shown in Fig. 3-I (b). As for the transportation of the multilayered vesicle from the oil into water phase, the manner of the transformation of the vesicle shows a marked difference depending on its stay-time at the interface. When the multilayered vesicle with thick wall is smoothly transported across the interface, the oil/water interface remains almost flat during the process of the transformation as in Fig. 3-I (c). On the other hand, when the vesicle is forced to stay in 
a narrow contact with the bulk interface, the process of peeling off of the thick wall is observed as in Fig. 3-I (d), (d'), which is schematically depicted in Fig. 3-II (d'). The spontaneous peeling of the droplet corresponds to the transfer of the outer surface toward the bulk water phase, which implies that the droplet existing in the bulk oil phase is covered by a thin water film. Regardless of the difference of the transformation processes, the water droplet with thick wall, a W/O CE, is transported into the water phase, by forming a vesicle, i.e. CL equipped with an oil layer. In our observation, the effect of lipid migration through the surface of the glass capillary seems to be negligible.

Figure 3-I (e) shows the collapse of a vesicle in the water phase (at $\mathrm{t}=1 \mathrm{~s}$ ) caused by a mechanical stress by use of a glass capillary, revealing that a small oil droplet is squeezed out from the wreck of vesicle $(t=5 \mathrm{~s})$. In this experiment, the thickness of the oil layer within the vesicle before the collapse is estimated to be $1-2 \mu \mathrm{m}$, as deduced from the volume of the squeezed oil droplet. In relation to the formation of the aqueous droplet covered by an oil layer, a recent report on the preparation of polymerosomes accompanied by vaporizing a volatile oil layer of double emulsions is to be noted [26]. 


\section{Conclusion}

Through microscopic observations we showed that a cell-sized

phospholipid vesicle can be transported between the water and oil phases forward and backward in a repetitive manner with the use of a micromanipulator. Characteristic changes in the lipid layer on the vesicle are observed accompanied by the change of its outer environment. As the next research target, it may of value to try to develop the methodology on the formation of asymmetric cell-sized liposome covered by a bilayer with different lipid composition between the inner and outer leaflets, by transporting a droplet with a monolayer of a certain lipid through a oil/water interface where a monolayer of the other lipid is existing.

\section{Acknowledgement}

This work was supported by a Grant-in-Aid for the 21st Century COE

"Center for Diversity and Universality in Physics" and a Grant-in-Aid for Scientific Research on Priority Areas (No.17076007) "System Cell Engineering by Multi-scale Manipulation" from the Ministry of Education, Culture, Sports, Science and Technology of Japan. M. Hase and A. Yamada were financially supported by Kyoto University Venture Business Laboratory and a Sasakawa Scientific Research Grant 
from The Japan Science Society, respectively. T. Hamada was supported by a Research Fellowship from the Japan Society for the Promotion of Science for Young Scientists (No. 16000653). We thank Prof. N. Kumazawa (Ibaraki University) and Prof. D. Baig1 (Ecole Normale Supérieure) for fruitful discussions. 


\section{References}

[1] M. S. Bretscher, Sci. Am. 253 (1985) 100.

(2) P. L. Luisi, P. Wakde, Giant Vesicles, John Wiley \& Sons Ltd, 2000.

[3] H. Hotani, F. Nomura, Y. Suzuki, Curr. Opin. Colloid Interface Sci. 4 (1999) 358.

[4] L. Limozin, A. Roth, E. Sackmann, Phys. Rev. Lett. 95 (2005) 178101.

[5] Y. Sato, S. M. Nomura, K. Yoshikawa, Chem. Phys. Lett. 380 (2003) 279.

[6] M. Michel, M. Winterhalter, L. Darbois, J. Hemmerle, J. C. Voegel, P. Schaaf, V. Ball, Langmuir 20 (2004) 6127.

[7] V. Noireaux, A. Libchaber, Proc. Natl. Acad. Sci. USA 101 (2004) 17669.

[8] S. M. Nomura, K. Tsumoto, T. Hamada, K. Akiyoshi, Y. Nakatani, K. Yoshikawa, ChemBioChem 4 (2003) 1172.

[9] D. T. Chui, C. F. Wilson, F. Ryttsén, A. Strömberg, C. Farre, A. Karlsson, S. Nordholm, A. Gaggar, B. P. Moki, A. Moscho, R. A. Garza-lópez, O. Orwar, R. N. Zare, Science 283 (1999) 1892.

[10] S. Kulin, R. Kishore, K. Helmerson, L. Locascio, Langmuir 19 (2003) 8206.

[11] F. Szoka, D. Papahadjopoulos, Proc. Natl. Acad. Sci. USA 75 (1978) 4194.

[12] D. Deamer, A. D. Bangham, Biochim. Biophys. Acta 443 (1976) 629.

[13] S. Matsumoto, M. Kohda, S. Murata, J. Colloid Interface Sci. 62 (1977) 149. 
[14] D. Papahadjopoulos, W. J. Vail, K. Jacobson, G. Poste, Biochim. Biophys. Acta 329 (1975) 483.

[15] H. H. Hub, U. Zimmermann, H. Ringsdorf, FEBS Lett. 140 (1982) 254.

[16] P. Mueller, T. F. Chien, B. Rudy, Biophys. J. 44 (1983) 375.

[17] N. Magome, T. Takemura, K. Yoshikawa, Chem. Lett. 26 (1997) 205.

[18] H. Hauser, Biochim. Biophys. Acta 772 (1984) 37.

[19] S. Pautot, B. J. Frisken, D. A. Weitz, Proc. Natl. Acad. Sci. USA 100 (2003) 10718

[20] S. Katsura, A. Yamaguchi, H. Inami, S. Matsuura, K. Hirano, A. Mizuno, Electrophoresis 22 (2001) 289.

[21] A. D. Griffiths, D. S. Tawfik, EMBO J. 22 (2003) 24.

[22] A. V. Pietrini, P. L. Luisi, ChemBioChem 5 (2004) 1055.

[23] M. Hase, A. Yamada, T. Hamada, K. Yoshikawa, arXiv/physics0605145 (2006).

[24] M. Hase, K. Yoshikawa, J. Chem. Phys. 124 (2006) 104903.

[25] S. Pautot, B. J. Frisken, D. A. Weitz, Langmuir 19 (2003) 2870.

[26] E. Lorenceau, A. S. Utada, D. R. Link, G. Cristobl, M. Joanicot, D. A. Weitz, Langmuir 21 (2005) 9183. 


\section{Figure Captions}

Fig 1. Schematic illustration on the experimental system with macroscopic two-phase system of water/oil/phospholipid.

Fig. 2. (a) Phase-contrast microscopic images on the process of the formation of a cell-sized water droplet in an oil phase. (b) Schematic picture on the experimental procedure. (c) Fluorescence microscopic image of a droplet observed just after the formation through the present method.

Fig. 3. I: Phase-contrast microscopic images. (a) A water droplet with a lipid layer, most probably a monolayer of phospholipids, is transferred into the water phase by forming a CL. (b) A CL is transported back to the oil phase by forming a W/O droplet. (c) A water droplet with a thick wall, or multilayered lipid film is transferred into the water phase by forming a CL. (d) A multilayered droplet (W/O CE) is transported to the interface and forced to stay there for a while. After the spontaneous transformation into a thinner droplet, the 'vesicle' is transported into the water phase. (e): A CL with a thick layer is collapsed by use of a glass capillary, showing the appearance of an oil droplet squeezed out from the vesicle. II: Schematic representation of the transformation of vesicles 
accompanied by the transportation through the bulk interface. 


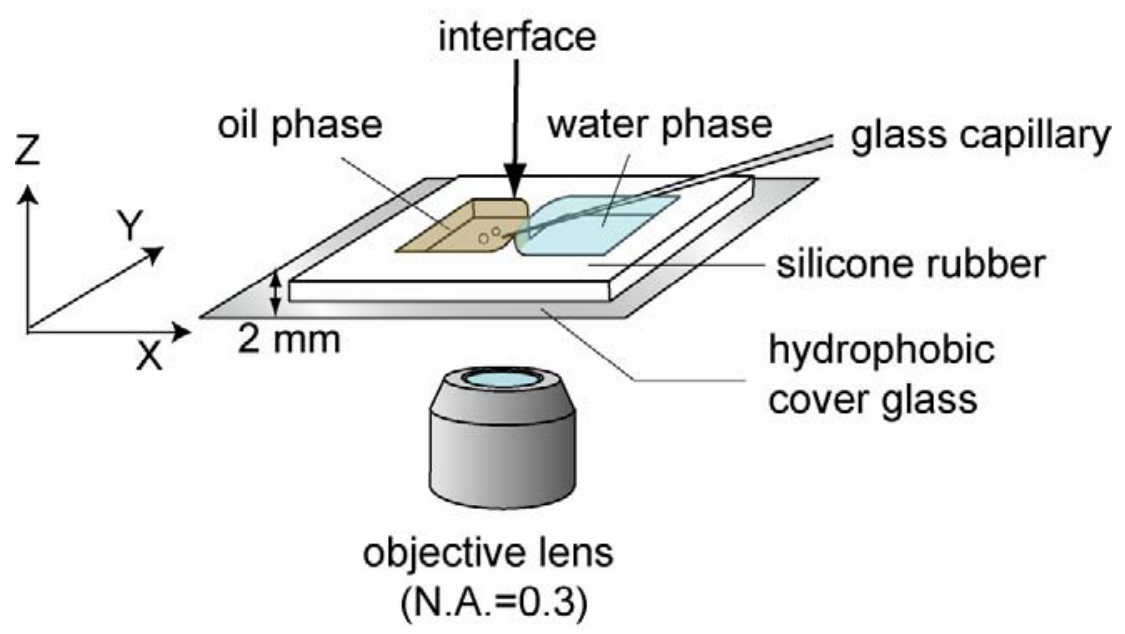

Figure 1 
(a)

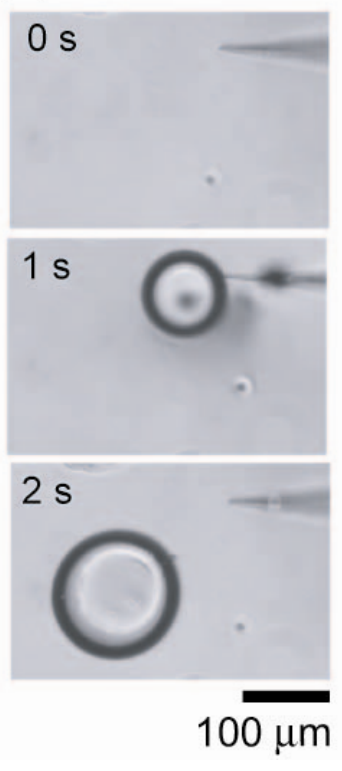

(b)

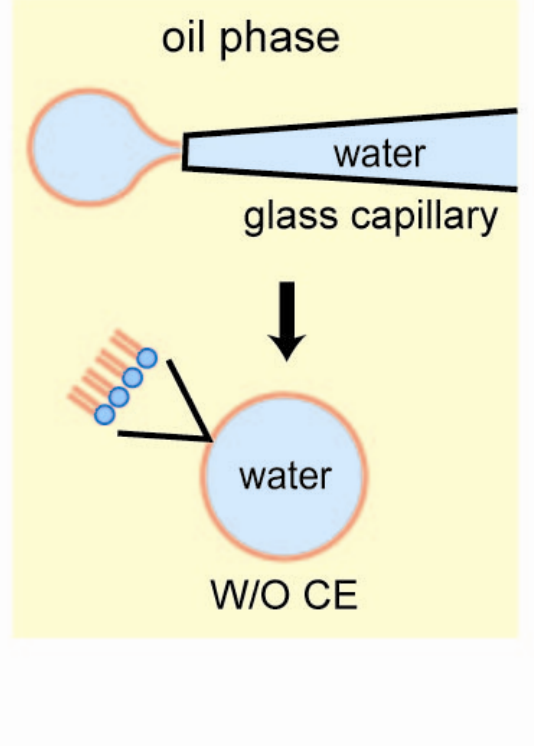

(c)

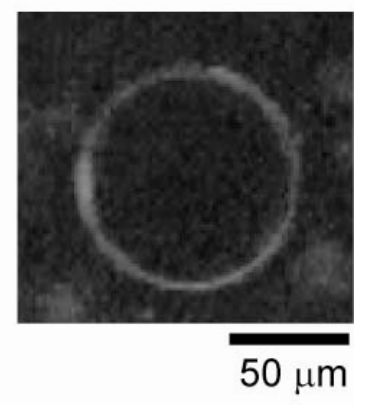

Figure 2 


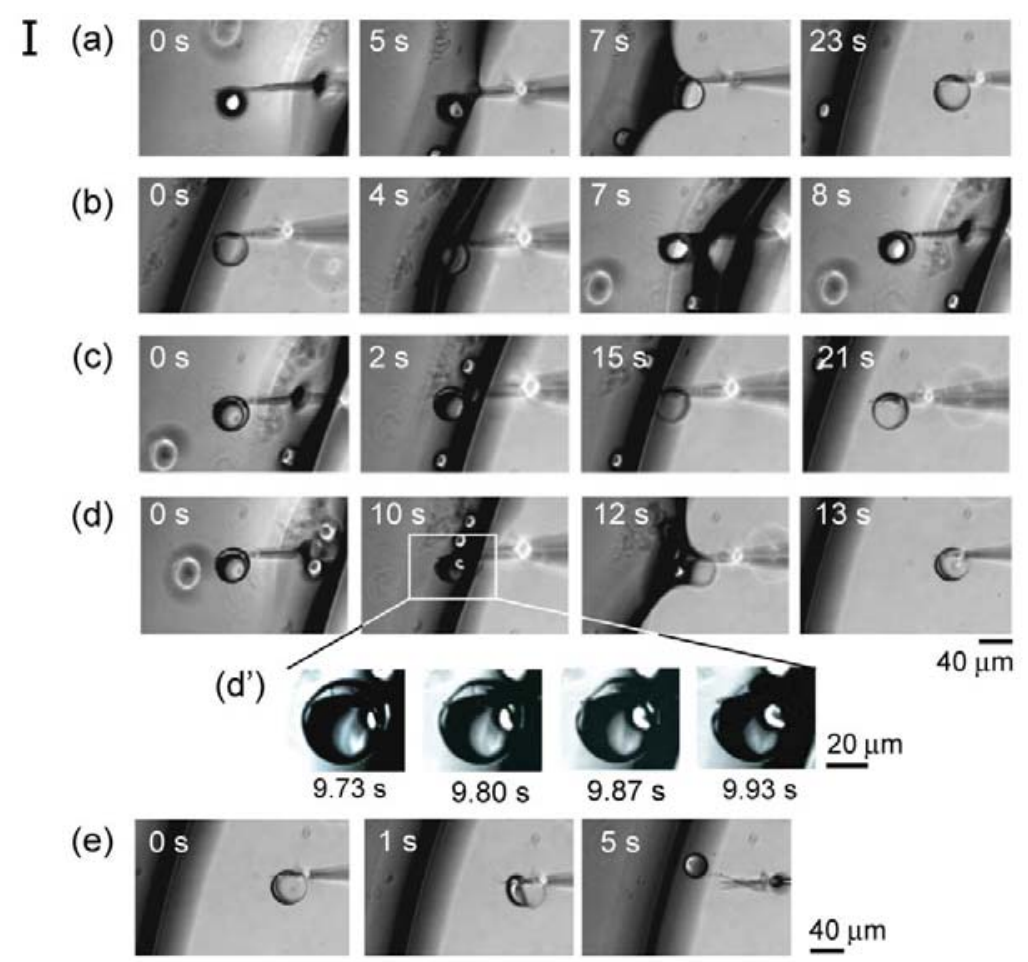

II
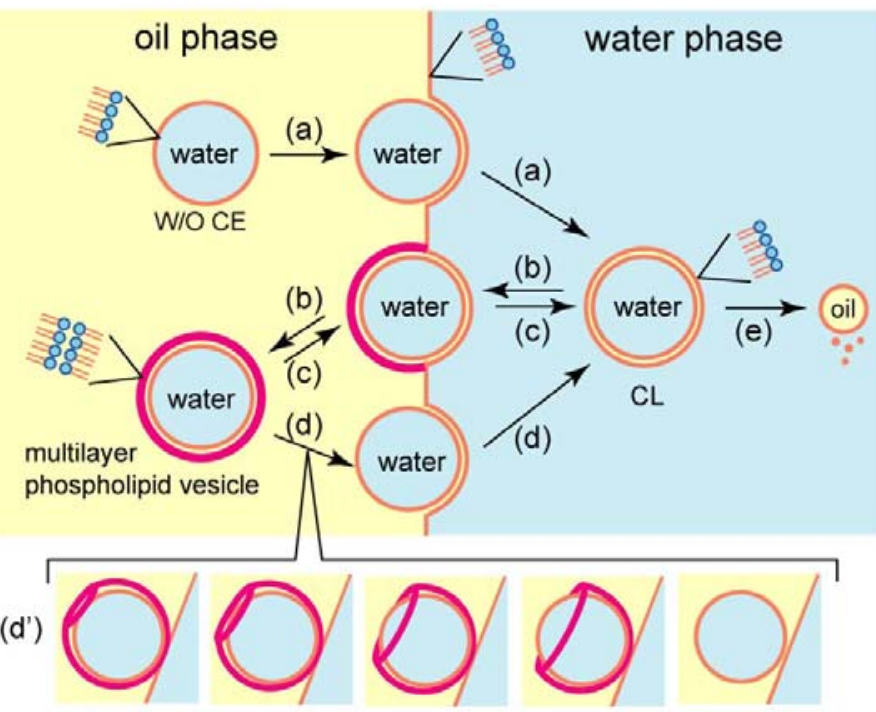

Figure 3 